\title{
Drying kinetics of dill leaves in a convective dryer
}

\author{
A. Motevali ${ }^{1}$, S. Younji ${ }^{2}$, R. Amiri Chayjan ${ }^{3}$, N. Aghilinategh ${ }^{2}$, and A. Banakar ${ }^{4}$ \\ ${ }^{1}$ Department of Engineering, Shahre Rey Branch, Islamic Azad University, Tehran, Iran \\ ${ }^{2}$ Department of Mechanical Engineering, Hamedan Branch, Islamic Azad University, Hamedan, Iran \\ ${ }^{3}$ Department of Agricultural Machinery Engineering, Bu-Ali Sina University, Hamedan, Iran \\ ${ }^{4}$ Department of Agricultural Machinery, Agricultural Faculty, Tarbiat Modares University,Tehran, Iran
}

Received December 1, 2011; accepted April 30, 2012

A b s t r a c t. Thin layer drying characteristics of dill leaves under fixed, semi-fluidized, and fluidized bed conditions were studied at air temperatures of $30,40,50$, and $60^{\circ} \mathrm{C}$. In order to find a suitable drying curve, 12 thin layer-drying models were fitted to the experimental data of the moisture ratio. Among the applied mathematical models, the Midilli et al. model was the best for drying behavior prediction in thin layer drying of dill leaves. To obtain the optimum network for drying of dill leaves, various numbers of multilayer feed-forward neural networks were made and tested with different numbers of hidden layers and neurons. The best neural network feed-forward back-propagation topology for the prediction of drying of dill leaves (moisture ratio and drying rate) was the 3-45-2 structure with the training algorithm trainlm and threshold functions logsig and purelin. The coefficient of determination for this topology for training, validation, and testing patterns was 0.9998, 0.9981, and 0.9990, respectively. Effective moisture diffusivity of dill leaves during the drying process in different bed types was found to be in the range from $7.1010^{-12}$ to $1.6210^{-10} \mathrm{~m}^{2} \mathrm{~s}^{-1}$. Also, the values of activation energy were determined to be between 75.435 and $80.118 \mathrm{~kJ} \mathrm{~mol}^{-1}$.

$\mathrm{K}$ e y w o r d s: drying kinetics, dill leaves, neural networks, mathematical model

\section{INTRODUCTION}

Drying is rated as an important post-harvest process for foods and fruits with respect to high consumption of energy and quality concerns. The final and major purpose is to minimize water activity and reduce microbial and chemical reactions. Sun drying is still used for drying fruits and vegetables in spite of considerable drawbacks such as long drying time, pollutions, product deterioration, and unwanted damage. These drawbacks are sufficient enough to substitute industrial and technological trends for drying in order to guarantee demands and preserve the quality (Doymaz, 2007).

*Corresponding author e-mail: Ali.motevali62@yahoo.com
In the fluidized bed drying method, the drying time is reduced rather than in the fixed bed method, due to the high heat and mass transfer between warm air and products (Giner and Calvelo, 1987). The advantages of fluidized bed drying are high heat and mass transfer rates, uniform temperature and bulk moisture content of particles, and excellent temperature control and operation up to the high ratio of mass of air to mass of product (Izadifar and Mowla, 2003). Fluidization is defined as suspending the vegetable bed (dill leaves, Anethum sowa L.) in air flow. With gradually increasing airflow through a bed of vegetable, fixed bed, minimum fluidized bed (semifluidized bed), bubbling fluidized bed and transportation will be created, respectively (Chayjan et al., 2011).

Several authors had attempted to determine mathematical models for estimation of the moisture ratio and drying rate of food and biological materials during the drying process in eg potato (Bakal et al., 2011), Cuminum cyminum (Zomorodian and Moradi, 2010), carrot (Doymaz, 2004), sweet cherry (Doymaz and Ismail, 2011), and berberies (Gorjian et al., 2011). Some researchers have studied the effective moisture diffusion and energy of activation in a thin layer drying of different agricultural products such as squash seeds (Chayjan et al., 2011), onion slices (Pathare and Sharma, 2006), or milky mushroom (Arumuganathan et al., 2009).

The neural network method has advantages compared to the common statistical and exact methods. This method, unlike linear regression models, does not force the values to be around the average value and therefore maintains the actual data variability. The neural network architecture consists of numerous simple and interrelated processors, namely neurons, and its structure is inspired by human brain (Alborzi, 2003). Factors such as temperature, airflow velocity, and 
duration of product exposure to the dryer exert an effect on the thin layer drying process (moisture ratio and drying rate) in different bed-type dryers (fixed, semifluidized, and fluidized). According to the dependent and independent variables in this research, no accurate relationship could be established, using the common methods, among these variables. Using the neural network models, the relationship between dependent and independent variables could be easily modeled for the process of drying dill leaves. Although much information has been reported about the mathematical model, neural networks, effective moisture diffusivity, and activation energy for various agricultural products, very little information is available on the mathematical model, neural networks, effective moisture diffusivity, and activation energy for dill leaves during fixed, semi fluidized, and fluidized convective drying.

The main aim of this research was to determine the activation energy and effective moisture diffusivity of dill leaves with a high moisture content for fixed, semi fluidized, and fluidized bed thin layer drying process.

\section{MATERIAL AND METHODS}

The drying experiments were conducted using a laboratory fluidized bed dryer. A centrifugal fan with an electrical motor $(0.375 \mathrm{~kW})$ supplied the required air flow. An electrical heating supply unit with $2 \mathrm{~kW}$ was designed to heat the inlet air. The drying chamber was drum type with the diameter and height of 150 and $320 \mathrm{~mm}$, respectively. Input air temperature control was carried out by a thermostat with $\pm 0.1^{\circ} \mathrm{C}$ accuracy (Atbin mega, made in Iran). Input air flow was performed using an inverter with $\pm 0.1 \mathrm{~Hz}$ accuracy (Vincker VSD2, made in Taiwan). Relative humidity of input air was measured by a hygrometer with accuracy of $\pm 3 \%$ RH (Lutron TM-903, made in Taiwan). Measuring and recording of fluidization characteristics of bed material (air velocity against pressure drop) was performed using Standard ST-8897 (made in China). The accuracy of this device was $\pm 0.1 \mathrm{~Pa}$ and $\pm 0.1 \mathrm{~m} \mathrm{~s}^{-1}$, in measuring differential pressure and air velocity, respectively. With regard to the thin layer drying condition and the dryer chamber area, about $6 \mathrm{~g}$ dill leaves (Anethum sowa L.) were used in the drying experiments. Fluidization curve has a minimum fluidized bed which its pressure drop against air velocity is maximum value. Fresh dill leaves were purchased from a local market. The leaf samples were stored in a refrigerator at $3 \pm 1^{\circ} \mathrm{C}$. Air relative humidity and ambient air temperature during drying changed from 25 to $35 \%$ and 27 to $33^{\circ} \mathrm{C}$, respectively. Input air temperature to the chamber was recorded during the experiments using a thermometer with accuracy of $\pm 0.1^{\circ} \mathrm{C}$ (Lutron TM-903, made in Taiwan). Four air temperature levels of $30,40,50$, and $60^{\circ} \mathrm{C}$ were selected to apply in the experiments. Moreover, with respect to three bed conditions, a total of 12 experiments were performed. The sample weight was recorded during the experiments using a digital balance (AND GF-6000, made in Japan) with $\pm 0.01 \mathrm{~g}$ accuracy. The weight measuring interval was $2 \mathrm{~min}$. The initial moisture content of dill leaves was determined using a gravimetric method at $60^{\circ} \mathrm{C}$ for $24 \mathrm{~h}$. The initial moisture content of dill leaves was 0.833 (d.b.). The final moisture content of the leaves after the drying process was about $0.06 \pm 0.01$ (w.b.). In order to determine pressure drops and airflow velocities of the dill leaves at the outlet, simultaneously, the fan speed was increased gradually using the inverter (Vincker VSD2) and the parameters were recorded. A differential digital manometer (Testo 505-P1) and a vane type digital anemometer were used for measuring static pressure loss and outlet air velocity, respectively. The maximum value of static pressure drop versus the specific air velocity in fluidization systems is defined as the minimum fluidization point or semifluidized bed (Kunii and Levenspiel, 1991). After determining the semi fluidized bed with air velocity of about $0.7 \mathrm{~m} \mathrm{~s}^{-1}$, one point before it (in fixed bed domain) was selected as a fixed bed condition with air velocity of $1.54 \mathrm{~m} \mathrm{~s}^{-1}$ and one point after that (in fixed bed domain) was selected as a fluidized bed condition with air velocity of $2.37 \mathrm{~m} \mathrm{~s}^{-1}$ and the drying experiments were conducted (Fig. 1).

Kinetic models are commonly developed based on the moisture ratio $(M R)$ normally characterized by centering attribute and better illustration. $M R$ is defined as Eq. (1):

$$
M R=\frac{M_{t}-M_{e}}{M_{o}-M_{e}},
$$

where: $M_{t}$ is the moisture content $\left(\mathrm{kg}_{\text {water }} \mathrm{kg}^{-1}\right.$ dry matter $)$ and $M_{e}$ and $M_{o}$ are equilibrium and primary moisture contents, respectively. Considering a negligible value of $M_{e}$ with respect to $M_{o}$ and $M_{t}$, the error of eliminating $M_{e}$ from Eq. (1) will be ignorable. Thus, Eq. (1) can be rewritten as Eq (2):

$$
M R=\frac{M_{t}}{M_{o}} .
$$

MATLAB 2007, the curve fitting toolbox environment, was employed to run standard drying curve fitting (Table 1) to the experimental data. It lists some of the standard models

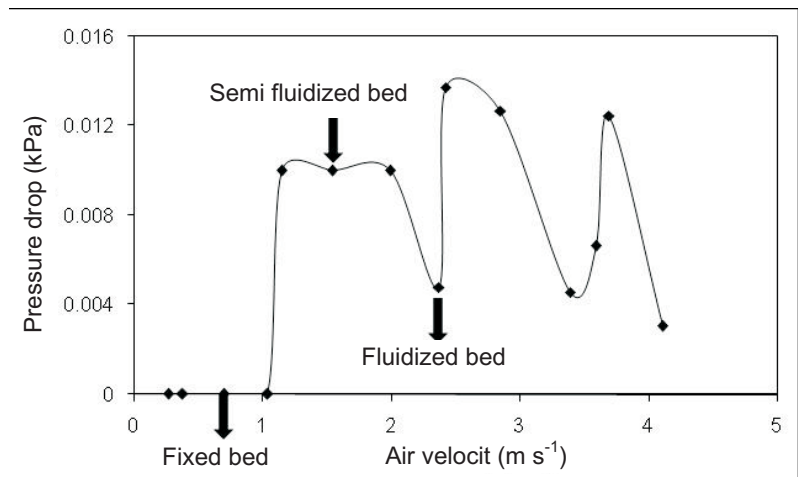

Fig. 1. Fluidization curve of dill leaves and selected points for modeling: $\mathrm{a}$ - fixed bed $\left(0.7 \mathrm{~m} \mathrm{~s}^{-1}\right), \mathrm{b}-$ semi fluidized bed $\left(1.54 \mathrm{~m} \mathrm{~s}^{-1}\right)$, $\mathrm{c}$ - fluidized bed $\left(2.37 \mathrm{~m} \mathrm{~s}^{-1}\right)$. 
T a b l e 1. Standard models reported in the literature used for drying of agricultural products

\begin{tabular}{rlll}
\hline No. & Model & Mathematical function & References \\
\hline 1 & Wang and Singh & $M R=a t^{2}+b t+c$ & Wang and Singh (1978) \\
2 & Verma et al. & $M R=a \exp (-k t)+(1-a) \exp (-g t)$ & Motevali et al. (2010) \\
3 & Henderson and Pabis & $M R=a \exp (-k t)$ & Motevali et al. (2010) \\
4 & Logaritmic & $M R=a \exp (-k t)+c$ & Dandamrongrak et al. (2002) \\
5 & Modified page & $M R=\exp \left(-(k t)^{n}\right)$ & Wang et al. (2007) \\
6 & Two term & $M R=a \exp \left(-k_{0} t\right)+b \exp \left(-k_{1} t\right)$ & Diamente and Munro (1991) \\
7 & Approximation of diffusion & $M R=a \exp (-k t)+(1-a) \exp (-k b t)$ & Ertekin and Yaldiz (2004) \\
8 & page & $M R=\exp \left(-k t^{n}\right)$ & Motevali et al. (2010) \\
9 & Modified Henderson and Pabis & $M R=a \exp (-k t)+b \exp (-g t)+c \exp (-h t)$ & Sharma et al. (2005) \\
10 & Newton & $M R=\exp (-k t)$ & Motevali et al. (2010) \\
11 & Midilli et al. & $M R=a \exp \left(-k t^{n}\right)+b t$ & Midilli et al. (2002) \\
12 & Two term exponential & $M R=a \exp (-k t)+(1-a) \exp (-k a t)$ & Motevali et al. (2010) \\
\hline
\end{tabular}

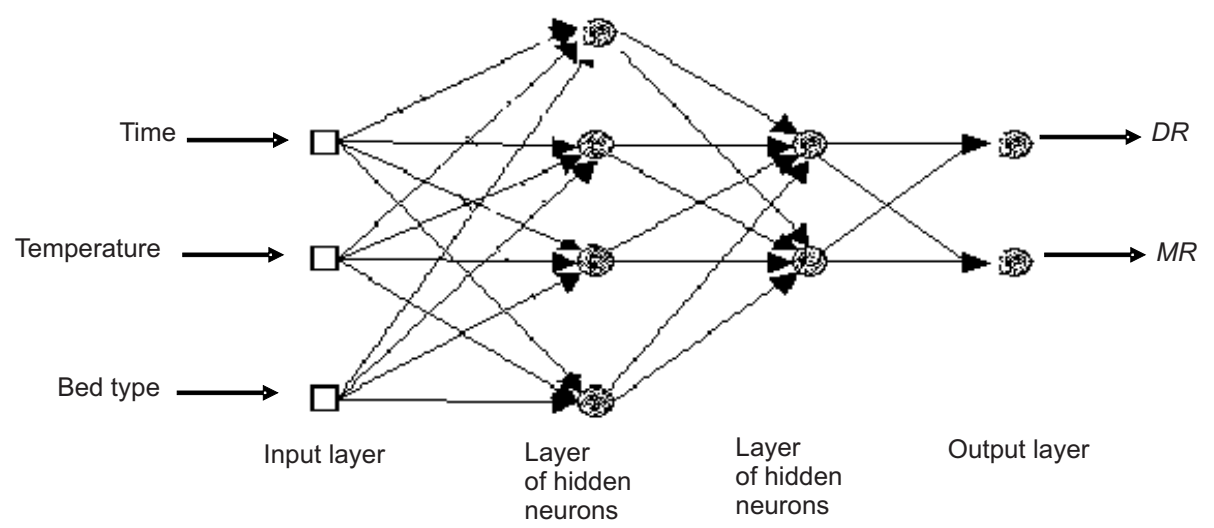

Fig. 2. Configuration of the multilayer neural network for predicting moisture ratio $(M R)$ and drying rate $(D R)$.

for thin layer drying of agricultural products. Figure 2 illustrates the structure of a multi layer feed-forward (MLFF) back-propagation ANN model for predicting the moisture ratio and drying rate of dill leaves during fixed, semi-fluidized and fluidized bed drying. First, different networks with different amounts of layers were used for this modeling. The dimensions of the input and output matrices were $3 \times 910$ and $2 \times 910$, respectively. The total amounts of the network input patterns are 910, which first were normalized and then were randomly divided into three groups, namely training (60\%), validation $(30 \%)$, and testing $(10 \%)$. The dimensions of the matrices for the three input patterns (training, validation, and testing) were $2 \times 637,2 \times 182$, and $2 \times 91$, respectively. In this research, the multilayer perceptron (MLP) networks with feed forward back propagation (FFBP) were used. This network is simple but at the same time highly practical due to its high accuracy. Various threshold functions, such as sigmoid (logsig), logarithmic (tangsig), and linear (purelin), and supervised learning algorithms, such as trainlm algorithm (Levenberg-Marquardt (LM)), traincsg, traingdx, trainrp, were used and their results were compared to determine the best structure for predicting the thin layer drying of dill leaves. Effective moisture diffusion was calculated as:

$$
M R=\frac{8}{\pi^{2}} \exp \left(-\frac{\pi^{2} D_{e f f} t}{4 L^{2}}\right),
$$

where: $M R$ - the moisture ratio (dimensionless), $t$-drying time, $D_{\text {eff }}$ - effective moisture diffusivity $\left(\mathrm{m}^{2} \mathrm{~s}^{-1}\right)$, and $L$ - thickness of dill leaves (m). Equation (3) has been used by many 
investigators to describe the effective moisture diffusivity coefficient (Doymaz, 2007). In this process, the thickness of dill leaves, $L$, is assumed to be constant.

Energy of activation was calculated as:

$$
D_{\text {eff }}=D_{o} \exp \left(-\frac{E_{a}}{\mathrm{R}_{\mathrm{g}} T_{a b s}}\right),
$$

where: $D_{o}$ - indicates Arrhenius coefficient $\left(\mathrm{m}^{2} \mathrm{~s}^{-1}\right), E_{a}-$ activation energy $\left(\mathrm{kJ} \mathrm{mol}^{-1}\right), T_{a b s}$ - absolute temperature $(\mathrm{K})$, and $\mathrm{Rg}$ - universal gas constant $\left(8.3143 \mathrm{~J} \mathrm{~mol}^{-1} \mathrm{~K}^{-1}\right)$.

\section{RESULTS AND DISCUSSIONS}

The required time for drying of dill leaves in different dryer bed types (fixed, semi-fluidized, and fluidized) is shown in Fig. 3. As shown in the following figures, in each bed type, with increasing temperature, the drying duration decreases since the thermal gradient inside the medium and the crop moisture evaporation rate increase. Also, at a constant temperature, increasing airflow velocity and changing crop bed type during drying, the drying duration decreases. This is because with increasing the airflow velocity, the environmental pressure decreases and consequently the internal moisture content faces little resistance in coming out and comes out at higher rates. Similar results were reported by other researchers (Chayjan et al., 2011; Motevali et al., 2010, 2011a, 2011b).

The initial moisture content of dill leaves was 73.1 on wet basis (w.b.). The moisture ratio $(M R)$ values at different temperatures and bed types were obtained using the Eq. (2). The $M R$ values obtained were fitted with the models presented in Table 1. Then the accuracy of different thin layer drying models was evaluated according to $\mathrm{R}^{2}$, SSE, and RMSE values, and the best model with the highest $R^{2}$ and the lowest SSE and RMSE was selected. The results obtained from fitting of the laboratory data with the proposed models showed that the Midilli et al. model predicts the drying process of dill leaves more accurately than the other models. The statistical coefficients and indices at the highest accuracy for different models at $60^{\circ} \mathrm{C}$ are presented in Table 2 .

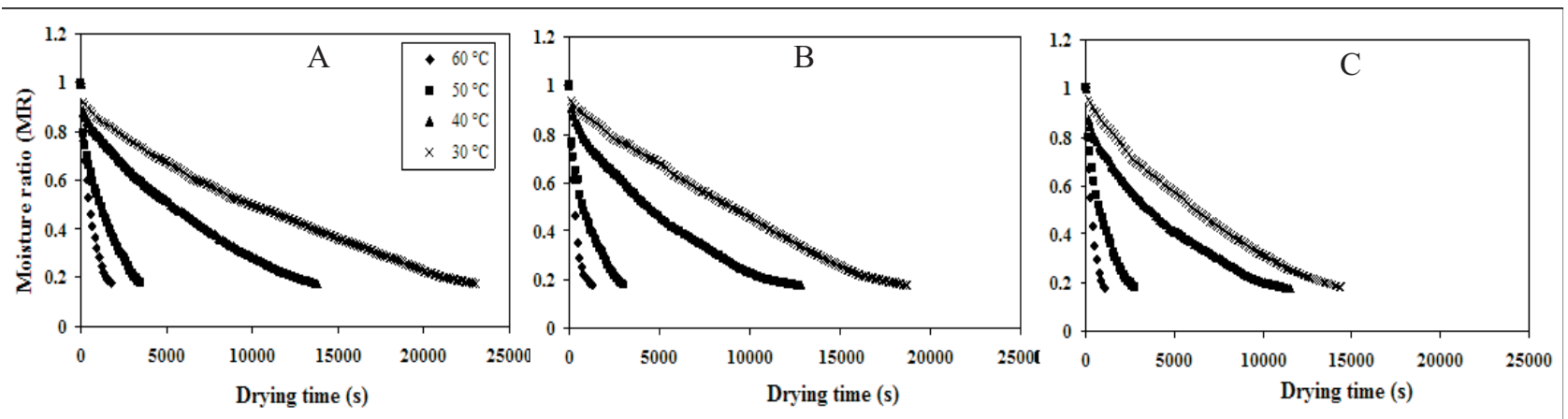

Fig. 3. Thin-layer drying curves of dill leave: A - fixed bed, B - semi fluid bed, C - fluid bed.

T a b l e 2. Optimum statistical criteria obtained from fitting experimental data to the predefined models

\begin{tabular}{|c|c|c|c|c|c|c|c|c|c|c|c|c|}
\hline \multirow{2}{*}{$\begin{array}{l}\text { Statistical } \\
\text { analysis }\end{array}$} & \multicolumn{12}{|c|}{ Model number } \\
\hline & 1 & 2 & 3 & 4 & 5 & 6 & 7 & 8 & 9 & 10 & 11 & 12 \\
\hline \multicolumn{13}{|c|}{ Fixed bed drying $\left(60^{\circ}\right)$} \\
\hline $\mathrm{R}^{2}$ & 0.9752 & 0.9449 & 0.97721 & 0.9620 & 0.98414 & 0.9910 & 0.9764 & 0.9809 & 0.9929 & 0.9718 & 0.9975 & 0.9080 \\
\hline SSE & 0.0035 & 0.00200 & 0.0012 & 0.00157 & 0.00167 & 0.00157 & 0.0011 & 0.0023 & 0.0017 & 0.0020 & 0.0015 & 0.0018 \\
\hline RMSE & 0.0026 & 0.00431 & 0.0030 & 0.00337 & 0.00397 & 0.00339 & 0.0027 & 0.0045 & 0.0036 & 0.0038 & 0.0093 & 0.0036 \\
\hline \multicolumn{13}{|c|}{ Semi fluid bed drying $\left(60^{\circ}\right)$} \\
\hline $\mathrm{R}^{2}$ & 0.9820 & 0.98034 & 0.98272 & 0.98034 & 0.98826 & 0.99153 & 0.9807 & 0.9891 & 0.9922 & 0.9775 & 0.9983 & 0.9781 \\
\hline SSE & 0.0095 & 0.00104 & 0.00104 & 0.00104 & 0.0014 & 0.0094 & 0.0010 & 0.0012 & 0.0014 & 0.0015 & 0.0013 & 0.0010 \\
\hline RMSE & 0.0300 & 0.03201 & 0.03172 & 0.03211 & 0.01195 & 0.03076 & 0.0325 & 0.0130 & 0.0379 & 0.0389 & 0.0127 & 0.0325 \\
\hline \multicolumn{13}{|c|}{ Fluid bed drying $\left(60^{\circ}\right)$} \\
\hline $\mathrm{R}^{2}$ & 0.9718 & 0.94374 & 0.96216 & 0.97068 & 0.97441 & 0.99194 & 0.9673 & 0.9788 & 0.9910 & 0.9723 & 0.9985 & 0.9706 \\
\hline SSE & 0.0008 & 0.00416 & 0.00145 & 0.00106 & 0.00116 & 0.00145 & 0.0014 & 0.0007 & 0.0010 & 0.0009 & 0.0009 & 0.0010 \\
\hline RMSE & 0.0284 & 0.0622 & 0.04373 & 0.03086 & 0.03057 & 0.03673 & 0.0362 & 0.0316 & 0.0307 & 0.0295 & 0.0124 & 0.0314 \\
\hline
\end{tabular}


T a b l e 3. Summary of the various ANN networks evaluated to yield the best determination coefficient $\left(\mathrm{R}^{2}\right)$ and mean square error (MSE)

\begin{tabular}{|c|c|c|c|c|c|c|c|c|c|}
\hline \multirow{2}{*}{$\begin{array}{l}\text { Activation } \\
\text { function }\end{array}$} & \multicolumn{2}{|c|}{ Neurons in hidden } & \multicolumn{3}{|c|}{$\mathrm{R}^{2}$} & \multicolumn{3}{|c|}{ MSE } & \multirow{2}{*}{ Epoch } \\
\hline & layer1 & layer2 & training & validation & test & training & validation & test & \\
\hline \multicolumn{10}{|c|}{ Trainlm } \\
\hline Log/Tan & 5 & 0 & 0.9906 & 0.9895 & 0.9894 & 0.0085 & 0.0108 & 0.0154 & 62 \\
\hline Log/Tan & 20 & 0 & 0.9967 & 0.9977 & 0.9972 & 0.0049 & 0.0062 & 0.0190 & 32 \\
\hline Log/Tan & 30 & 0 & 0.9973 & 0.9896 & 0.9956 & 0.0040 & 0.0201 & 0.0077 & 21 \\
\hline Log/pure & 45 & 0 & 0.9998 & 0.9981 & 0.9990 & 0.0054 & 0.0055 & 0.0067 & 66 \\
\hline Log/pure & 35 & 0 & 0.9997 & 0.9990 & 0.9979 & 0.0021 & 0.0086 & 0.0133 & 86 \\
\hline Log/Tan/Tan & 10 & 10 & 0.9966 & 0.9974 & 0.9980 & 0.0063 & 0.0047 & 0.0168 & 24 \\
\hline Log/Tan/Tan & 35 & 20 & 0.9982 & 0.9973 & 0.9975 & 0.0031 & 0.0110 & 0.0123 & 27 \\
\hline Log/Tan/Tan & 40 & 10 & 0.9985 & 0.9952 & 0.9978 & 0.0027 & 0.0175 & 0.0051 & 17 \\
\hline Log/Pure/pure & 10 & 30 & 0.9994 & 0.9947 & 0.9943 & 0.0025 & 0.0152 & 0.0070 & 110 \\
\hline Log/Pure/pure & 40 & 30 & 0.9992 & 0.9989 & 0.9978 & 0.0055 & 0.0072 & 0.0057 & 26 \\
\hline Log/Pure/pure & 15 & 15 & 0.9991 & 0.9918 & 0.9976 & 0.0028 & 0.0116 & 0.0121 & 22 \\
\hline \multicolumn{10}{|c|}{ Traingdx } \\
\hline Log/Tan & 5 & 0 & 0.9431 & 0.9418 & 0.9278 & 0.0314 & 0.0348 & 0.0469 & 62 \\
\hline Log/Tan & 25 & 0 & 0.8953 & 0.8832 & 0.8704 & 0.0579 & 0.0686 & 0.0829 & 54 \\
\hline Log/Tan & 45 & 0 & 0.8865 & 0.8787 & 0.8389 & 0.0615 & 0.067 & 0.1008 & 16 \\
\hline Log/pure & 35 & 0 & 0.9155 & 0.9206 & 0.8917 & 0.0484 & 0.0416 & 0.0647 & 35 \\
\hline Log/pure & 15 & 0 & 0.8737 & 0.8679 & 0.8675 & 0.0628 & 0.0744 & 0.0612 & 55 \\
\hline Log/Tan/Tan & 10 & 5 & 0.6990 & 0.7227 & 0.6953 & 0.1487 & 0.1334 & 0.1477 & 39 \\
\hline Log/Tan/Tan & 25 & 15 & 0.7353 & 0.7253 & 0.7366 & 0.1326 & 0.1448 & 0.1424 & 17 \\
\hline Log/Tan/Tan & 40 & 25 & 0.7776 & 0.7272 & 0.7045 & 0.1345 & 0.1848 & 0.1757 & 13 \\
\hline Log/Pure/pure & 15 & 10 & 0.7719 & 0.7800 & 0.7575 & 0.1192 & 0.1316 & 0.1137 & 29 \\
\hline Log/Pure/pure & 30 & 30 & 0.8772 & 0.8846 & 0.8608 & 0.0691 & 0.0773 & 0.0693 & 31 \\
\hline Log/Pure/pure & 45 & 25 & 0.9451 & 0.9122 & 0.8945 & 0.0214 & 0.0676 & 0.0455 & 33 \\
\hline \multicolumn{10}{|c|}{ Trainrp } \\
\hline Log/Tan & 10 & 0 & 0.9787 & 0.9798 & 0.9779 & 0.0142 & 0.0216 & 0.0164 & 123 \\
\hline Log/Tan & 35 & 0 & 0.9862 & 0.9681 & 0.9730 & 0.0098 & 0.0228 & 0.0215 & 151 \\
\hline Log/Tan & 50 & 0 & 0.9705 & 0.9634 & 0.9632 & 0.0151 & 0.0265 & 0.0229 & 59 \\
\hline Log/pure & 45 & 0 & 0.9829 & 0.9907 & 0.9860 & 0.0141 & 0.0073 & 0.0112 & 97 \\
\hline Log/pure & 25 & 0 & 0.9951 & 0.9963 & 0.9970 & 0.0066 & 0.0060 & 0.0188 & 139 \\
\hline Log/Tan/Tan & 35 & 20 & 0.9725 & 0.9837 & 0.9740 & 0.0210 & 0.0101 & 0.0140 & 66 \\
\hline Log/Tan/Tan & 50 & 25 & 0.9872 & 0.9915 & 0.9620 & 0.0110 & 0.0072 & 0.0234 & 59 \\
\hline Log/Tan/Tan & 20 & 45 & 0.9783 & 0.9861 & 0.9827 & 0.0175 & 0.0085 & 0.0136 & 126 \\
\hline Log/Pure/pure & 15 & 10 & 0.9958 & 0.9872 & 0.9850 & 0.0048 & 0.0166 & 0.0139 & 179 \\
\hline Log/Pure/pure & 25 & 15 & 0.9834 & 0.9744 & 0.9713 & 0.0120 & 0.0209 & 0.0213 & 154 \\
\hline Log/Pure/pure & 40 & 30 & 0.9850 & 0.9781 & 0.9609 & 0.0101 & 0.0195 & 0.0258 & 204 \\
\hline
\end{tabular}


T a b l e 3. Continuation

\begin{tabular}{|c|c|c|c|c|c|c|c|c|c|}
\hline \multirow{2}{*}{$\begin{array}{l}\text { Activation } \\
\text { function }\end{array}$} & \multicolumn{2}{|c|}{ Neurons in hidden } & \multicolumn{3}{|c|}{$\mathrm{R}^{2}$} & \multicolumn{3}{|c|}{ MSE } & \multirow{2}{*}{ Epoch } \\
\hline & layer1 & layer2 & training & validation & test & training & validation & test & \\
\hline \multicolumn{10}{|c|}{ Trainscg } \\
\hline Log/Tan & 5 & 0 & 0.9429 & 0.9546 & 0.9508 & 0.0382 & 0.0282 & 0.0257 & 35 \\
\hline Log/Tan & 30 & 0 & 0.9735 & 0.9653 & 0.9677 & 0.0200 & 0.0243 & 0.0288 & 48 \\
\hline Log/Tan & 45 & 0 & 0.9603 & 0.9429 & 0.9675 & 0.0231 & 0.0405 & 0.0200 & 27 \\
\hline Log/pure & 25 & 0 & 0.9825 & 0.9774 & 0.9409 & 0.009 & 0.0198 & 0.0577 & 0.0577 \\
\hline Log/pure & 35 & 0 & 0.9846 & 0.9761 & 0.9753 & 0.0119 & 0.0219 & 0.0166 & 92 \\
\hline Log/Tan/Tan & 15 & 5 & 0.9709 & 0.9508 & 0.9346 & 0.0208 & 0.0399 & 0.0506 & 26 \\
\hline Log/Tan/Tan & 25 & 20 & 0.9554 & 0.9713 & 0.9452 & 0.0288 & 0.0245 & 0.0368 & 43 \\
\hline Log/Tan/Tan & 35 & 45 & 0.9802 & 0.9782 & 0.9873 & 0.0153 & 0.0362 & 0.0076 & 127 \\
\hline Log/Pure/pure & 20 & 20 & 0.9651 & 0.9428 & 0.957 & 0.0224 & 0.0469 & 0.0372 & 39 \\
\hline Log/Pure/pure & 45 & 35 & 0.9616 & 0.9721 & 0.9579 & 0.0262 & 0.0373 & 0.022 & 52 \\
\hline Log/Pure/pure & 50 & 40 & 0.9838 & 0.9718 & 0.979 & 0.0119 & 0.0274 & 0.0152 & 86 \\
\hline
\end{tabular}

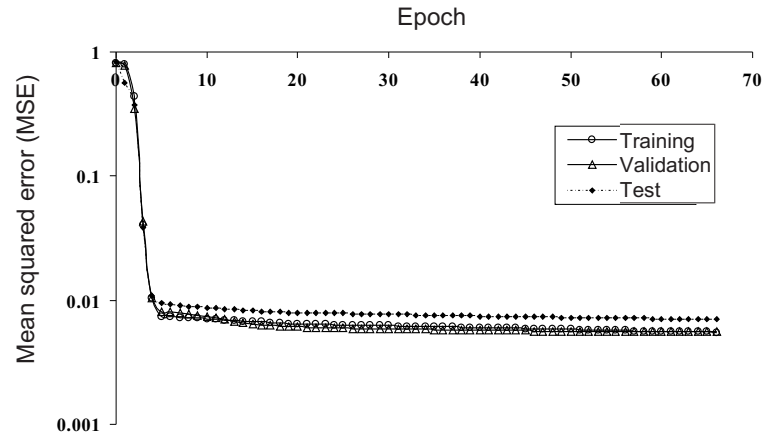

Fig. 4. Training error curve.

Table 2 summarizes a list of the best neural network topology structure, threshold functions, and different applied algorithms in predicting $M R$ and $D R$ for drying of dill leaves. As shown in the mentioned table, most applied topologies and threshold functions have proper training and validation errors. In fact, it could be asserted that the neural networks are a powerful tool for modeling of drying of dill leaves in different conditions, which have a high accuracy and low cost and time. The main reason of neural networks convergence might be the large amount of the network input patterns.

Among the different topologies presented in Table 3, the neural network with 3-45-0-2 structure, logsig and purelin transfer functions, and the Levenberg-Marquardt training algorithm (trainlm) had the lowest error and the highest coefficient of determination. Figure 4 shows the training curve (error) and the network for the training, validation, and testing stages for the best network. The network errors (MSE) for training, validation, and testing patterns of this topology are $0.0054,0.0055$, and 0.0067 , respectively. This network becomes convergent through 66 epochs in $3.383 \mathrm{~s}$ with an error of training equals to 0.00229 . The regression analysis showed that $\mathrm{R}^{2}$ for training, validation, and testing patterns was $0.9998,0.9981$, and 0.9990, respectively.

Figure 5 indicates MSE variations in regard to variations in the number of neurons at the middle layer for purelin and logsig transfer functions and the Levenberg-Marquardt training algorithm (trainlm) in training, validation, and testing, respectively. Generally, according to Fig. 5, it could be stated that the increasing number of neurons at the middle layer decreases the network error. But the network's convergence duration increases. Figure 6 shows the convergence duration with the epoch changes for the best network with 2-45-0-2 topology. Also, the diagram other axis shows the gradient descent changes with epoch. As it is shown, the gradient descent decreases as the epoch increases, so that it reaches its minimum at epoch 66 and the network becomes convergent with the desired topology. In order to compare the output results of the best mathematical model (Midilli et al. model) with the results from the neural network, a linear fitting (regression) was performed on the dependent parameters of drying of dill leaves. The comparison between the moisture ratios obtained from the experiment and the moisture ratios predicted by the model, in different tested drying temperatures and bed types, is presented in Fig. 7 for drying of dill leaves. As shown in the figure, a line at angle of 45 is fitted to data, which shows the accuracy of the Midilli et al. model in predicting dill leaves moisture ratio variation for different dryer bed types (fixed, semi-fluidized, fluidized). 
A

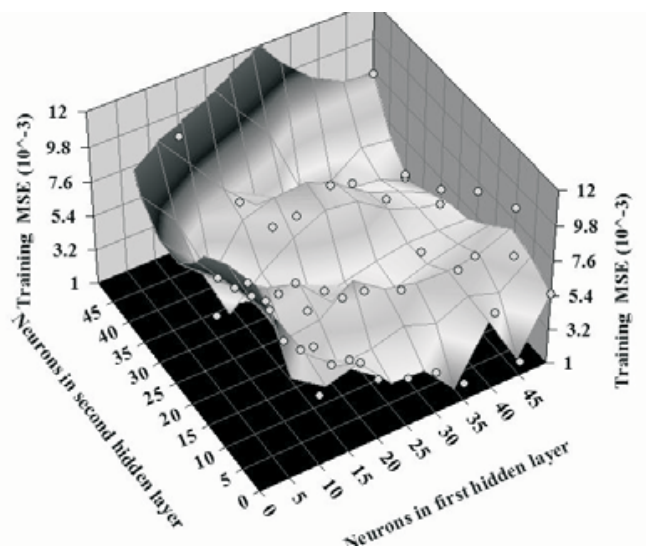

B

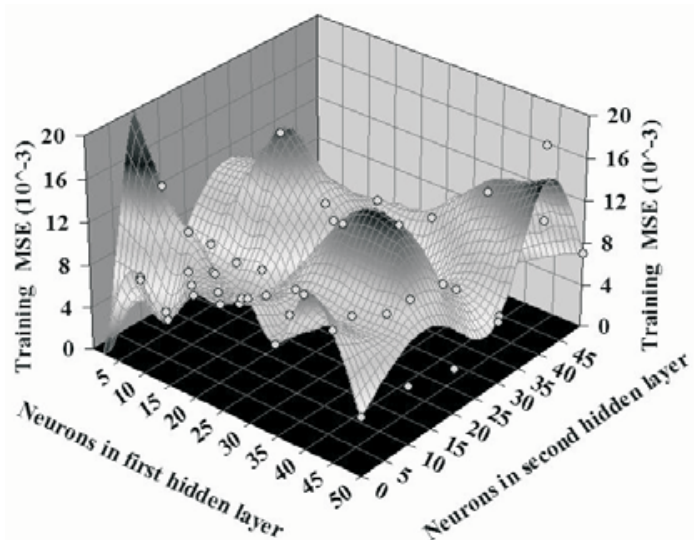

$\mathrm{C}$

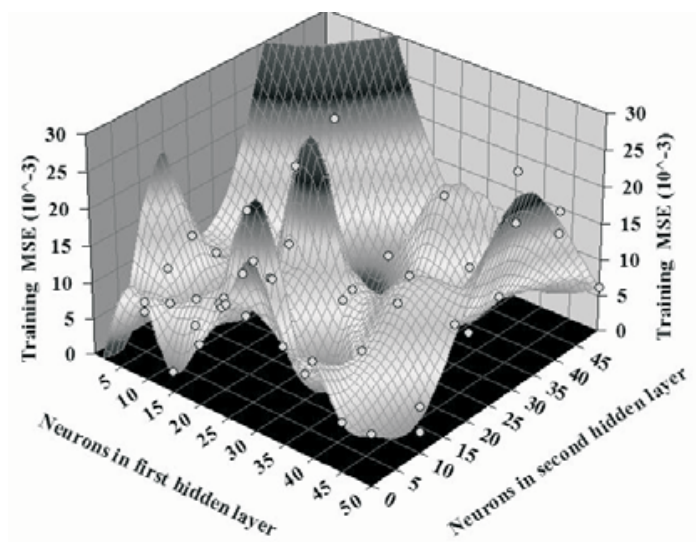

Fig. 5. Effect of the number of hidden neurons in the 1st and 2nd layers on learning: $\mathrm{A}$ - performance, $\mathrm{B}$ - validation, $\mathrm{C}$ - test of ANN models.
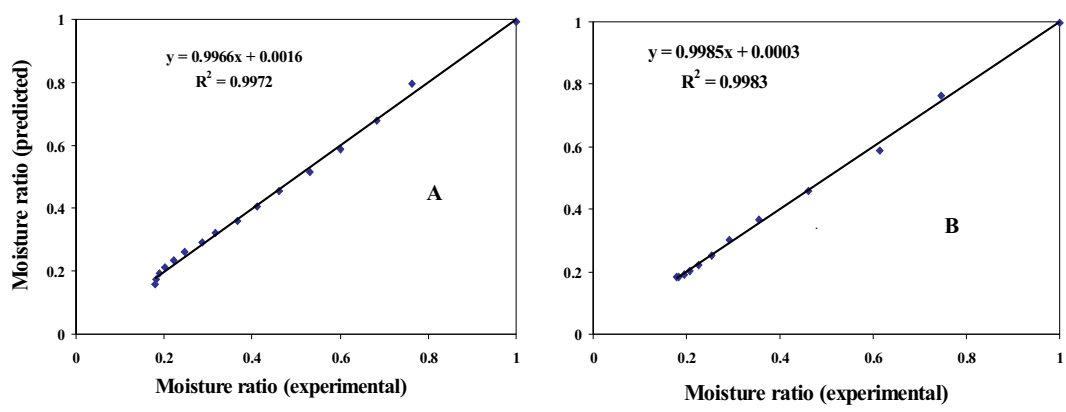

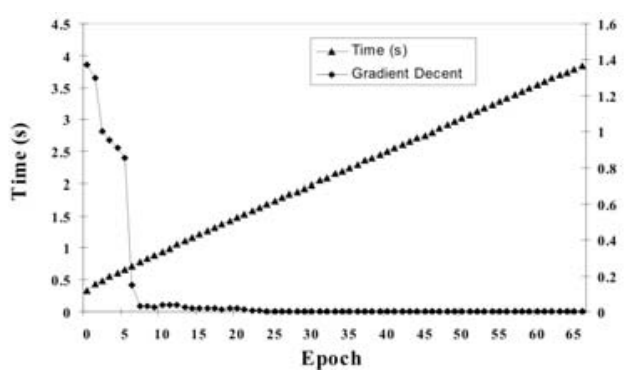

Fig. 6. Variation of time and gradient decend with epoch.

The residuals plot seen in Fig. 8 was also used to evaluate the Midilli et al. model. Plotting the residuals against the predicted values of the dimensionless moisture ratio, there were no systematic patterns. The proximity of residuals around zero line shows the sufficiency of the derived model. Figure 9 indicates the regression analysis for the verification test of the $D R$ and $M R$ parameters in drying of dill leaves in different drying conditions using the neural networks. The $\mathrm{R}^{2}$ value for $D R$ and $M R$ was 0.9967 and 0.9928 , respectively, and MSE for these parameters was minimal.

Comparison of Figs 7 and 9 demonstrates that both neural networks and mathematical models have good accuracy in modeling the process of drying dill leaves. But since the number of variables (inputs and outputs) in the neural networks is higher than the mathematical models and also since the modeling duration is shorter in neural networks, it could be concluded that the neural networks are a powerful tool in modeling different drying conditions for dill leaves.

Figure 10 displays natural logarithms of the moisture ratio $\ln (M R)$ against time (second) at constant airflow velocity and different temperature levels. As shown in every figure, drying of dill leaves occurs only as a course with a descending rate, and this means that liquid diffusion is the stimulus controlling the drying process. Therefore, all the curves are in the form of straight lines. Effective moisture diffusivity is calculated using the line slope method and represented in Table 4. With increasing air temperature and velocity (changing the drying bed from the fixed to the fluidized state), the relative moisture content of dill leaves was decreased due to higher mass and heat transfer within

Fig. 7. Comparison between the experimental moisture ratios and those predicted by the Midilli et al. model in the: A-fixed bed, $\mathrm{B}-$ semi fluid bed, C - fluid bed. 


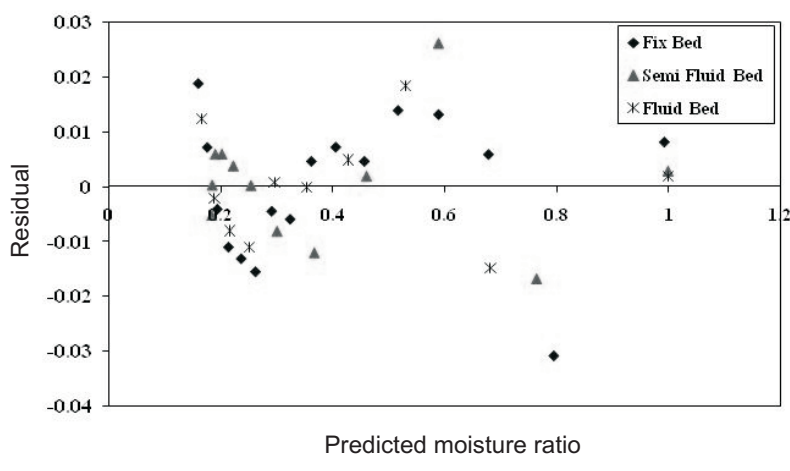

Fig. 8. Residuals versus predicted values of the moisture ratio derived by multiple.
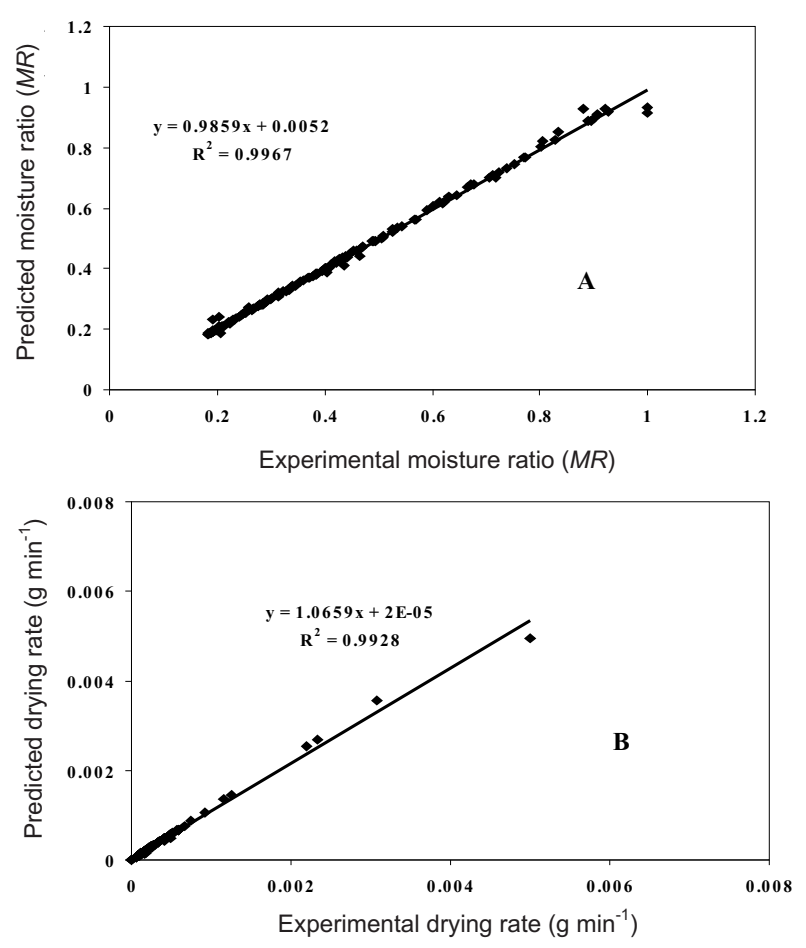

Fig. 9. Correlation between the experimental data and the predicted values of the ANN model for prediction of: A - moisture ratio, B - drying rate $\left(\mathrm{g} \mathrm{min}^{-1}\right)$. the dryer. Calculations proved that effective moisture diffusivity was highly correlated with hot air temperature and bed types (velocity). The trend demonstrated in Fig. 10 shows that at each drying bed type, effective moisture diffusivity increases as the air temperature increases, so that the highest air velocity (fluidized bed) and temperature levels resulted in the highest effective moisture diffusivity. Plot of $\ln \left(D_{\text {eff }}\right)$ versus $1 / \mathrm{T}$ is presented in Fig. 11. The activation energy for dill leaves was calculated by means of linear regression. The maximum and minimum values of activation energy during the drying (fixed, semi-fluidized, and fluidized bed) process were obtained as $75.435-80.118 \mathrm{~kJ} \mathrm{~mol}^{-1}$.

According to Table 5 , increasing air velocity and changing the dill bed type during drying increases the activation energy amount. This behavior could be due to the aerodynamic effects according to the specific flow pattern as well as changes in the dill bed type during drying from the fixed state to the fluidized state.

\section{CONCLUSIONS}

1. The drying process of dill leaves was comprehensively investigated in this research. Several pretreatments and types of drying bed were employed to achieve a precise idea of drying of dill leaves. Furthermore, the Midilli et al. model fitted best to the experimental data compared to the other standard models reported on drying of agricultural products.

2. The analysis of the experimental data in the three drying bed types by the ANN revealed that there was a good correlation between the ANN-predicted results and the experimental data. Therefore, ANN proved to be a useful tool for correlation and simulation of fixed, semi-fluidized, and fluidized drying bed parameters in the case of dill leaves. Generally, ANN proved to be a reliable alternative for sour cherries thin-layer drying prediction due to its generality and simplicity.

3. Moisture diffusivity increased as air temperature and velocity (changing from the fixed bed to the fluidized drying bed) increased. Also, the activation energy increased with increasing air velocity (changing from the fixed bed to the fluidized drying bed).

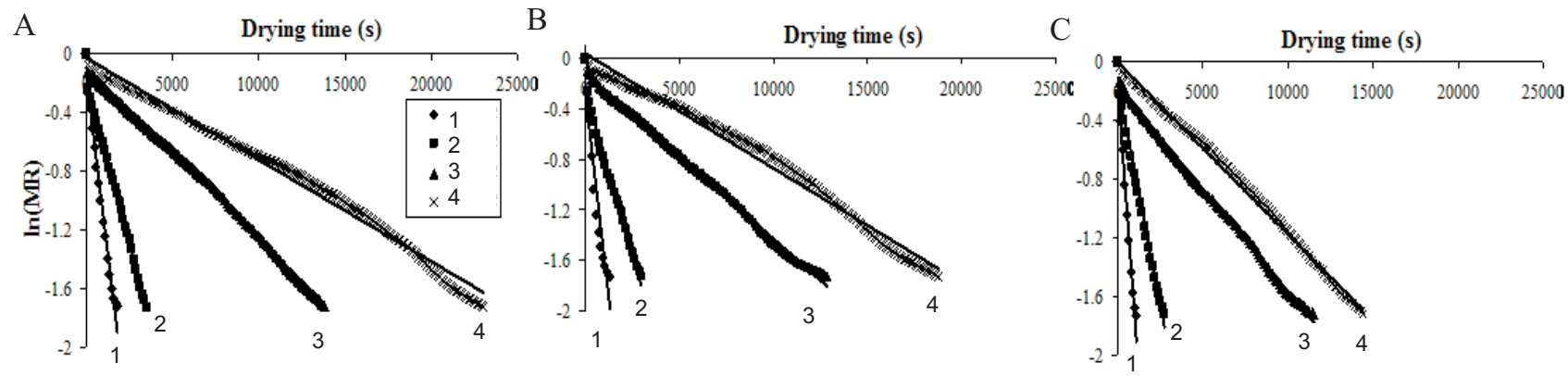

Fig. 10. Plot of $\ln (M R)$ versus time (s) at the: A - fixed bed, B - semi fluid bed, $\mathrm{C}$ - fluid bed. 
T a b l e 4. Effective moisture diffusivity and $\mathrm{R}^{2}$ values at various air temperature and bed drying

\begin{tabular}{ccccccc}
\hline \multirow{2}{*}{$\begin{array}{c}\text { Temperature } \\
\left({ }^{\circ}\right)\end{array}$} & Fixed & $\mathrm{R}^{2}$ & Semi fluid & $\mathrm{R}^{2}$ & Fluid & $\mathrm{R}^{2}$ \\
\cline { 2 - 7 } & $7.1010^{-12}$ & 0.988 & $9.1310^{-12}$ & 0.984 & $1.0410^{-11}$ & 0.996 \\
40 & $1.0110^{-11}$ & 0.997 & $1.5110^{-11}$ & 0.997 & $2.0710^{-11}$ & 0.996 \\
50 & $5.0710^{-11}$ & 0.994 & $5.0710^{-11}$ & 0.985 & $6.0910^{-11}$ & 0.990 \\
60 & $1.0110^{-10}$ & 0.981 & $1.3210^{-10}$ & 0.925 & $1.6210^{-10}$ & 0.994 \\
\hline
\end{tabular}

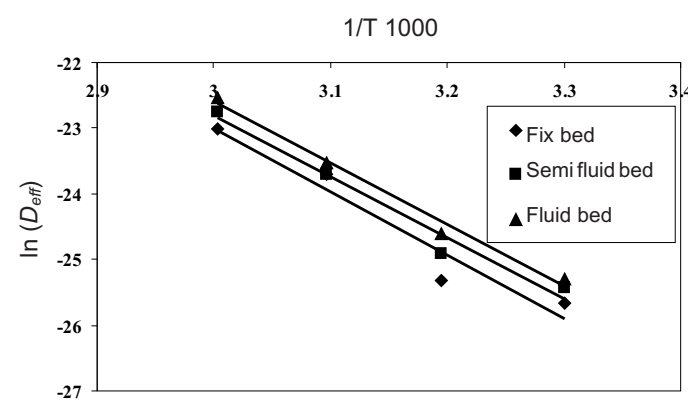

Fig. 11. Effect of bed types on the activation energy in thin-layer drying of dill leaves.

T a b l e 5. Activation energy and related correlation coefficient at different bed drying for thin-layer drying of dill leaves

\begin{tabular}{lccc}
\hline \multirow{2}{*}{ Variables } & \multicolumn{3}{c}{ Type of bed } \\
\cline { 2 - 4 } & Fixed & Semi fluid & Fluid \\
\hline$E_{a}\left(\mathrm{~kJ} \mathrm{~mol}^{-1}\right)$ & 80.118 & 77.954 & 75.435 \\
$\mathrm{R}^{2}$ & 0.939 & 0.970 & 0.988 \\
$D_{o}$ & 5.91 & 4.99 & 5.53 \\
\hline
\end{tabular}

\section{REFERENCES}

Alborzi M., 2003. Introduction with Neural Networks. Sharif University of Technology Press, Tehran, Iran.

Arumuganathan T., Manikantan M.R., Rai R.D., Anandakumar S., and Khare V., 2009. Mathematical modeling of drying kinetics of milky mushroom in a fluidized bed dryer. Int. Agrophys., 23, 1-7.

Bakal S.B., Sharma G.P., Sonawane S.P., and Verma R.C., 2011. Kinetics of potato drying using fluidized bed dryer. J. Food Sci. Technol., DOI 10.1007/s13197-011-0328-X.

Chayjan R.A., Salari K., Abedi Q., and Sabziparvar A.A., 2011. Modeling moisture diffusivity, activation energy and specific energy consumption of squash seeds in a semi fluidized and fluidized bed drying. J. Food Sci. Technol., DOI 10.1007/s13197-011-0399-8.

Dandamrongrak R., Young G., and Mason R., 2002. Evaluation of various pre-treatments for the dehydration of banana and selection of suitable drying models. J. Food Eng., 95, 139-146.
Diamente L.M. and Munro P.A., 1991. Mathematical modeling of hot air drying of sweet potato slices. Int. J. Food Sci. Technol., 26, 99-109.

Doymaz I., 2004. Convective air drying characteristics of thin layer carrots. J. Food Eng., 61, 359-364.

Doymaz I., 2007. Influence of pretreatment solution on the drying of sour cherry. J. Food Eng., 78, 591-596.

Doymaz I. and Ismail O., 2011. Drying characteristics of sweet cherry. Food Bioprod. Proces., 89, 31-38.

Ertekin C. and Yaldiz O., 2004. Drying of eggplant and selection of a suitable thin layer drying model. J. Food Eng., 63, 349-359.

Giner S.A. and Calvelo A., 1987. Modeling of wheat drying on fluidized beds. J. Food Sci., 52, 1358-1363.

Izadifar M. and Mowla D., 2003. Simulation of a cross-flow continuous fluidized bed dryer for paddy rice. J. Food Eng., 58, 325-329.

Kunii D. and Levenspiel O., 1991. Fluidisation Engineering. Butterworth-Heinemann, London, UK.

Midilli A., Kucuk H., and Yapar Z., 2002. A new model for single-layer drying. Drying Technol., 20(7), 1503-1513.

Motevali A., Minaei S., Khoshtaghaza M.H., and Amirnejat H., 2011a. Comparison of energy consumption and specific energy requirements of different methods for drying mushroom slices. Energy, 36, 6433-6441.

Motevali A., Najafi G.H., Abbasi S., Minaei S., and Ghaderi A., 2011b. Microwave-vacuum drying of sour cherry: comparison of mathematical models and artificial neural networks. J. Food Sci. Technol., DOI 10.1007/s13197-011-0393-1.

Motevali A., Minaei S., Khoshtaghaza M.H., Kazemi M., and Nikbakht A.M., 2010. Drying of pomegranate arils: comparison of predictions from mathematical models and neural networks. Int. J. Food Eng., 6(3), Article 15, 1-19.

Pathare P.B. and Sharma G.P., 2006. Effective moisture diffusivity of onion slices undergoing infrared convective drying. Biosyst. Eng., 93, 285-291.

Wang C.Y. and Singh R.P., 1978. Use of variable equilibrium moisture content in modeling rice drying. Trans. ASAE, 11, 668-672.

Wang Z., Sun J., Liao X., Chen F., Zhao G., Wu J., and Hu X., 2007. Mathematical modeling on hot air drying of thin layer apple pomace. Food Res. Int., 40, 39-46.

Zomorodian A. and Moradi M., 2010. Mathematical modeling of forced convection thin layer solar drying for Cuminum cyminum. J. Agri Sci. Tech., 12, 401-408. 